Araştırma Makalesi - Research Article

\title{
Bölgesel-Evrişimsel Sinir Ağları ile Retina Görüntülerindeki Lezyonların Tespiti
}

\author{
Süleyman Uzun ${ }^{1 *}$ \\ Geliş / Received: 28/01/2020 \\ Revize / Revised: 09/03/2020 \\ Kabul / Accepted: 26/03/2020 \\ $\ddot{\mathbf{O Z Z}}$ \\ Şeker hastalığı gözün yapısını etkileyen ve görme kayıplarına sebep olan bir hastalıktır. Göz yapısında çok \\ çeşitli lezyon türlerinin oluşmasına neden olur. Retina görüntüleri üzerinde bulunan bu lezyonlar farklı \\ hastalıkların belirtisi olmaktadır. Bu hastalıkların başında en bilineni diyabetik retinopati rahatsızlığıdır. $\mathrm{Bu}$ \\ rahatsızlığı erken teşhis ve tedavisinde lezyonların tespiti oldukça önemli olmaktadır. Yapılan çalışmada, retina \\ görüntüleri üzerinde bulunan lezyonların tespiti için Bölgesel-Evrişimsel Sinir Ağları temelli bilgisayar destekli \\ tespit sistemi önerilmiştir. Önerilen bu sistemle göz hastalıkları alanda çalışan uzmanların teşhis ve tedavisine \\ destek olması hedeflenmiştir. Çalışmada kullanılan retina görüntüleri STARE, DIARETDB0 ve DIARETDB1 \\ veri tabanlarından elde edilmiştir. Kullanılan veri tabanlarında bulunan görüntülerin \%70'i eğitim ve \%30'u test \\ görüntüsü olarak ayrılmıştır. Bölgesel-Evrişimsel Sinir Ağları, eğitim aşamasında çok fazla veriye ihtiyaç \\ duymasından dolayı eğitim görüntülerin etiketlenmesi amacıyla dikdörtgen şeklinde ve tek görüntü üzerinden \\ birden fazla alanın seçilmesine imkan sağlayan bir bölge seçicide tasarlanmıştır. Retina görüntüleri derin \\ öğrenme uygulamalarında sıkça kullanılan cifar-10 ön-eğitimli ağı üzerinde eğitilmiştir. Eğitimler sonunda \\ yapılan test işlemlerinde STARE, DIARETDB0 ve DIARETDB1 veri tabanlarında sırasıyla lezyonu bölgeyi \\ bulma başarımları \%91, \%98.53 ve \%93.01 doğruluk ile başarılı bir şekilde tespit etmiştir.
}

Anahtar Kelimeler-Retina Görüntüleri, Bölgesel-Evrişimsel Sinir Ağları, Derin Öğrenme, R-CNN

1*Sorumlu yazar iletişim: suleyman.uzun@bilecik.edu.tr (https://orcid.org/0000-0001-8246-6733)

Bilgisayar Mühendisliği Bölümü, Bilecik Şeyh Edebali Üniversitesi, Mühendislik Fakültesi, Bilecik, Türkiye 


\title{
Detection of Lesions On Retinal Images Using The Regional- Convolutional Neural Networks
}

\begin{abstract}
Diabetes is a disease that affects the structure of the eye and causes vision loss. It causes a wide variety of lesion types in the eye structure. It causes a wide variety of lesion types in the eye structure. These lesions on the retina images are symptoms of different diseases. The most well-known of these diseases is diabetic retinopathy. Detection of lesions is very important in early diagnosis and treatment of this ailment. In the study, a computerassisted detection system based on Regional-Evolutionary Neural Networks has been proposed for the detection of lesions on the retinal images. With this proposed system, it is aimed to support the diagnosis and treatment of specialists working in the field of eye diseases. Retina images used in the study were obtained from STARE, DIARETDB0 and DIARETDB1 databases. $70 \%$ of the images in the databases used are devoted to education and 30\% to test images. Regional-Evolutionary Neural Networks are designed in a region selector that allows multiple areas to be selected over a single image in order to tag educational images since they require a lot of data during the training phase. Retina images are trained on the cifar-10 pre-trained network, which is frequently used in deep learning practices. In the test operations performed at the end of the trainings, STARE, DIARETDB0 and DIARETDB1 databases successfully detected the lesion in the database with $91 \%, 98.53 \%$ and $93.01 \%$ accuracy, respectively.
\end{abstract}

Keywords- Retina images, Regional-Convolutional Neural Network, Deep Learning, R-CNN 


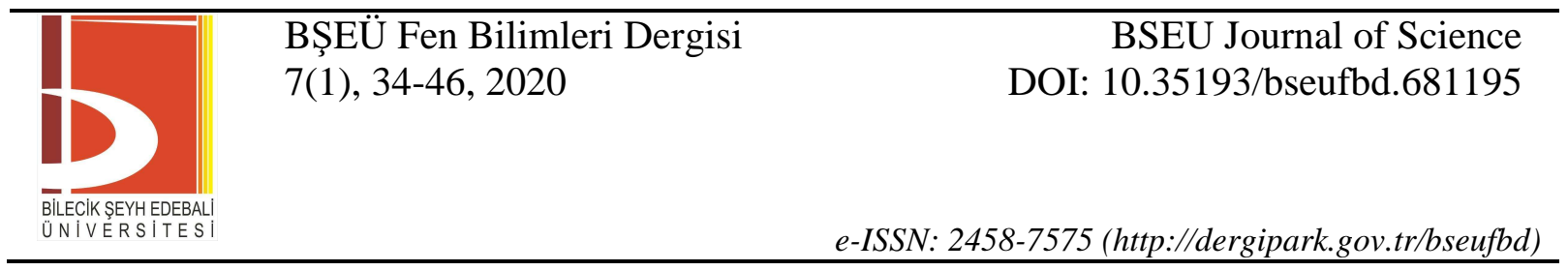

\section{GİRIŞ}

Retina üzerinde bulunan lezyonlar farklı hastalıkların sebebi olabilmektedir. Diyabetik retinopati (DR), maküler dejenerasyonu, glukoma vb. Özellikle DR hastalı̆̆ zamanında tedavi edilmesi gereken bir göz hastalığıdır. Bu hastalığın erken teşhisi retina üzerindeki lezyonlara bakılarak yapılabilmektedir. Eğer zamanında tedavi edilmezse görme kayıplarına yol açabilmektedir [1]. Dünya üzerindeki bütün körlük vakalarının \%5'i DR hastalığından kaynaklanmaktadır [2]. Bu sebeplerden dolayı retina üzerindeki lezyonların zamanında tespit edilmesi ileride olabilecek hastalıkların önüne geçilmesi ve körlük vakalarının azalmasına katkı sağlayacaktır. Uzmanlar bu lezyonları tespit etmek için kamera yardımıyla retina görüntülerini alıp inceleyerek ve lezyonlara bakarak hastalıkları teşhis etmektedirler. Uzmanların yoğun çalışma tempolarında teşhis sürecinde bazı lezyonların gözden kaçırabilmektedirler. Bu sebeplerden dolayı yapılan bu çalışma ile lezyonların tespiti için Bölgesel-Evrişimsel Sinir Ağları (B-ESA) temelli Bilgisayar Destekli Tespit Sistemi (BDTS) önerilmiştir. Önerilen bu sistem ile göz hastalıkları alanında çalışan uzmanlara destek olunması amaçlanmıştır.

Literatürde retina görüntüleri üzerindeki lezyonların tespit edilmesi amacıyla farklı teknikler kullanılmaktadır. Singh vd. yaptıkları çalışmada [3], retina görüntülerini DR hastalığının olup olmaması şeklinde iki farklı sınıf ve DR hastalığının 5 aşamasına göre beş farklı sınıfta derin öğrenme tekniklerinden Evrişimsel sinir ağları (ESA) ile sınıflandırmışlardır. İki sınıf için başarımlarını \% 71 ve beş sınıf için başarımlarını \%56 olarak hesaplamışlardır. Kasım [4], retina görüntüleri üzerinde bulunan lezyonların tespiti için retina görüntüleri adaptif histogram eşitleme ve medyan filtreden geçirerek çok seviyeli otsu yöntemiyle 5 ayrı alana bölmektedir. Dördüncü alanda yer alan lezyonlu bölgeyi Markov Rastsal alanı oluşturarak yenilenmiş koşullu model ile analiz etmektedir. STARE ve DRIVE veritabanlarından seçtiği 53 hastalıklı 27 sağlıklı görüntü ile hastalıklı görüntülerdeki lezyonların \%86 başarımla tahmin etmiş ve sağlık görüntüler üzerinde herhangi bir lezyonun olmadığını ise \%96 başarımla tahmin etmiştir. Quellec vd. [5], DR'nin ilk belirtisi olan mikroanevrizmaların (microaneurysms) saptanması ve yaşa bağlı maküler dejenerasyonu damgasını taşıyan drusen'in tespit edilmesi için bir çerçeve sunmuşlardır. Mikroanevrizmaların tespitini \%92, drusen'in tespitini ise $\% 85$ doğruluk ile tespit etmişlerdir. Rocha vd. [1], retina görüntüleri üzerindeki DR ile ilişkili kırmızı ve parlak lezyonların özel bir ön işlem gerektirmeden tespit edebilecek bir algoritma sunmuşlardır. Deneysel çalışmalarında \%88.1 ve \%89.3'lük bir başarım elde etmişlerdir. Murugan vd. [6], DR'nin ilk ve klinik belirtisi olan Retinal Mikroanevrizmalar'ı giriş retina görüntüler arasından lokalize etmek için otomatik bir sistem önermektedirler. Çalışmalarında DIREVE, STARE ve DIARETDB0 veri setlerini kullanmışlardır. Mevcut sistemlerle karşılaştıııldıklarında daha kısa zaman almaktadır ve DR'nin tarama işlemine yardımcı olduğu gözlemlenmiştir. Atilla vd. [7], DR hastalarının retinalarıdaki eksuda lezyonlarını otomatik olarak tespit etmek amacıyla SURF anahtar nokta algoritması ile özellik çıkartımı yaparak Destek Vektör Makineleri, Çok Katmanlı Algılayıcılar ve Rasgele Orman Algoritması ile lezyonları tespit etmişlerdir. DIARETDB0 ve DIARETDB1 veri tabalarında bulunan görüntüler üzerinde yaptıkları deneylerde sırasıyla \%95.8 ve \%92.4 doğrulukla Rasgele Orman Algoritması en başarılı sonucu verdiğini gözlemlemişlerdir. Carrera vd. [8], DR'yi önceden tespit etmek amacıyla retina görüntülerinin sayısal olarak işlenmesi temeline dayanan bilgisayar destekli bir tanı önermektedirler. Bu sayede proliferative olmayan DR'nin derecesini otomatik olarak sınıflandırmayı hedeflemişlerdir. Sınıflandırmak için Destek Vektör Makinelerini kullanmışlardır. Deneysel çalışmalarda Messidor veri setini kullanmışlardır. Yaptıkları çalışma sonucunda \%94.6 başarım elde etmişlerdir.

Tablo 1. Retina görüntüleri üzerindeki lezyon tespiti için yapılan çalışmalar

\begin{tabular}{cll}
\hline Çalışmalar & \multicolumn{1}{c}{ Uygulanan Metot } & Başarım \\
\hline Singh vd. 2019 [3] & Evrişimsel sinir ağları & $\% 71$ \\
Murugan vd. 2019 [6] & Kendilerinin önerdiği bir metot & - \\
Kasım 2018 [4] & Adaptif histogram eşitleme ve Otsu algoritması & $\% 86$ \\
Rocha vd. 2012 [1] & Kendilerinin önerdiği bir metot & $\% 88.1-\% 89.3$ \\
Quellec vd. 2011 [5] & Kendilerinin önerdiği bir metot & $\% 85-\% 92$ \\
Atilla vd. 2020 [7] & Destek Vektör Makineleri, Çok Katmanlı Algılayıcılar ve Rasgele & $\% 95.8-\% 92.4$ \\
& Orman Algoritmasi & $\% 94.6$ \\
\hline Carrera vd. [8] & Destek Vektör Makineleri & \\
\hline
\end{tabular}


Nesne tanıma işlemi, bir görüntü içerisinde nesnenin görüntünün neresinde olduğu ve kapladığı alanın sınırlarının tespiti olarak tanımlanabilir. B-ESA da nesne tanıma işlemlerinde literatürde sıkça kullanılan ve yüksek başarımlar elde edilen bir derin öğrenme modelidir. Dandıl vd. [9], daha hızlı B-ESA kullanarak, sığırların yüz görüntülerini sınıflandırarak tanınması işlemlerini gerçekleştirmişlerdir. Deneysel çalışmalarında beş farklı sığıra ait 1129 görüntüyü eğitim, 450 görüntüyü test işlemlerinde kullanmışlardır. Sığır yüz görüntülerini ön-eğitimli ağ üzerinde eğitimlerini gerçekleştirdikten sonra test işlemlerinde \%98.44 doğruluk ile sınıflandırmışlardır. Kürşat ve Dandıl [10], 23 farklı hastaya ait 1218 Bilgisayarlı Tomografi (BT) kesitinden elde edilen görüntülerden 99 tanesini iyi huylu, 115 tanesini kötü huylu olmak üzere toplam 214 adet görüntüyü etiketlemişlerdir. Bu görüntülerin 160 tanesini eğitim, 54 tanesini ise test için kullanmışlardır. Ön eğitilmiş ağlar yardımıyla ESA kullanarak iyi huylu ve kötü huylu nodüller olarak sınıflandırmışlar ve \%75 test başarımı elde etmişlerdir. Arı vd. [11], beyin MR görüntülerinden beyinde bulunan tümörü ve tümörün yerini belirten bilgisayar destekli otomatik tümör tespit sistemi geliştirmişlerdir. Geliştirdikleri sistem B-ESA tabanlı olup dört farklı şekilde sistem geliştirmişlerdir. Bütün testlerini Benchmark, Rembredant ve Harvard veri setleri üzerinde gerçekleştirmişlerdir. En iyi sonucu \%99.10 ile B-ESA4 mimarisi ile Benchmark veri setinden elde etmişlerdir. Dandıl ve Polattimur [12], köpek davranışlarının tespit edilerek sınıflandırılması amacıyla daha hızlı B-ESA'ya dayalı bir sistem önermişlerdir. Yapılan deneysel çalışmalarda ağız açma hareketini \%94, dil çıkarma hareketini \%98, koklama hareketini \%99.33, kulak dikme hareketini \%99.33, kuyruk sallama hareketini \%98 ve oyun oynama davranışını \%98.67 doğrulukla tespit etmişlerdir.

Bu çalışmada, global veri setleri içerisinde bulunan retina görüntüleri üzerindeki lezyonların tespit edile bilmesi için B-ESA tabanlı bir BDTS önerilmiştir. Önerilen sistem ile diğer yapılan çalışmalara göre daha iyi başarım sonuçları elde edilmiştir. Önerilen B-ESA sisteminin başarımını arttırmak amacıyla, her bir görüntü üzerinden farklı noktalarda bulunan lezyonlu bölgeler üzerinde etiketleme yapılmıştır. Tek lezyonlu bölge seçimine göre B-ESA'nın başarımının \%75'lerden ortalama \%90 ve üzerine çıktığı gözlemlenmiştir. Önerilen BDTS'nin teşhis ve karar alma noktalarında bu alanın uzmanlarına yardımcı olabileceği öngörülmektedir.

\section{METARYAL VE YÖNTEM}

Bu çalışmada kullanılan retina görüntüleri üzerindeki lezyonları tespit etmek amacıyla STARE [13], [14] veri setinde bulunan görüntüler kullanılmıştır. Eğitim aşamasında kullanılan görüntüler MATLAB ortamında geliştirilmiş dikdörtgen şekilde alan seçebilen bir uygulama ile etiketlenmiştir. Bu uygulama, retina görüntüleri üzerinde farklı noktalarda çok fazla lezyon olduğu için tek bir görüntü üzerinde birden fazla alanı seçebilecek şekilde tasarlanmıştır. Veri setindeki görüntülerin bir kısmı eğitim için bir kısmı ise test amacıyla ayrılmıştır. Sadece eğitim için kullanılan görüntüler üzerinde etiketleme işlemleri yapılarak derin öğrenme ağı eğitilmiştir. Sonrasında daha derin öğrenme ağının test görüntüleri üzerindeki lezyonlu bölgeleri bulması sağlanmıştır. Ağın eğitim için kullanılabilecek cifar-10/cifar-100 ön eğitilmiş alar kullanılabilir. Cifar-10, veri büyütme yapılmadan sınıflandırma başarımı cifar-100'e göre çok daha yüksek olduğu için tercih edilmiştir. Cifar-10 ön eğitilmiş ağ, 10 sınıf, 50.000 adet eğitim görüntüsü ve 10.000 adet test görüntüsü kullanılarak eğitilmiş bir ağdır [15].

Önerilen sistemin BDTS'nin mimarisi ve akış şeması Şekil 1'de görülmektedir. STARE veri seti içerisindeki sağlıklı görüntüler çıkartılarak tamamen hastalıklı görüntüler elde edilmiştir. Bunlar içerisinden \%30 ve \%70 olarak ayrılacak 20 adeti test görüntüsü olarak ayrılmış ve geriye kalan 338 görüntü eğitim görüntüsü olarak ayrılmıştır. Bu eğitim görüntüleri üzerinde birden fazla ve dağınık şekilde lezyonlar bulunmaktadır. Bütün bu lezyonları etiketlemek amacıyla MATLAB ortamında tek bir görüntü üzerinden birden fazla alanı seçen bir yazılım geliştirildi. Bu yazılımla tek bir retina görüntüsü üzerinde bulunan bütün lezyonlar tek tek etiketlenmiştir. Etiketlenen eğitim görüntüleri cifar-10 ön eğitilmiş ağ kullanılarak eğitime tabi tutulmuştur. Son aşamada ise 20 adet test görüntüsü üzerinde test edilmiştir. 


\begin{tabular}{|c|c|c|}
\hline & $\begin{array}{l}\text { BŞEÜ Fen Bilimleri Dergisi } \\
7(1), 34-46,2020\end{array}$ & $\begin{array}{l}\text { BSEU Journal of Science } \\
\text { DOI: } 10.35193 / \text { bseufbd } 681195\end{array}$ \\
\hline & & 58-7575 (http://dergipark.gov.tr/bseufbd) \\
\hline
\end{tabular}

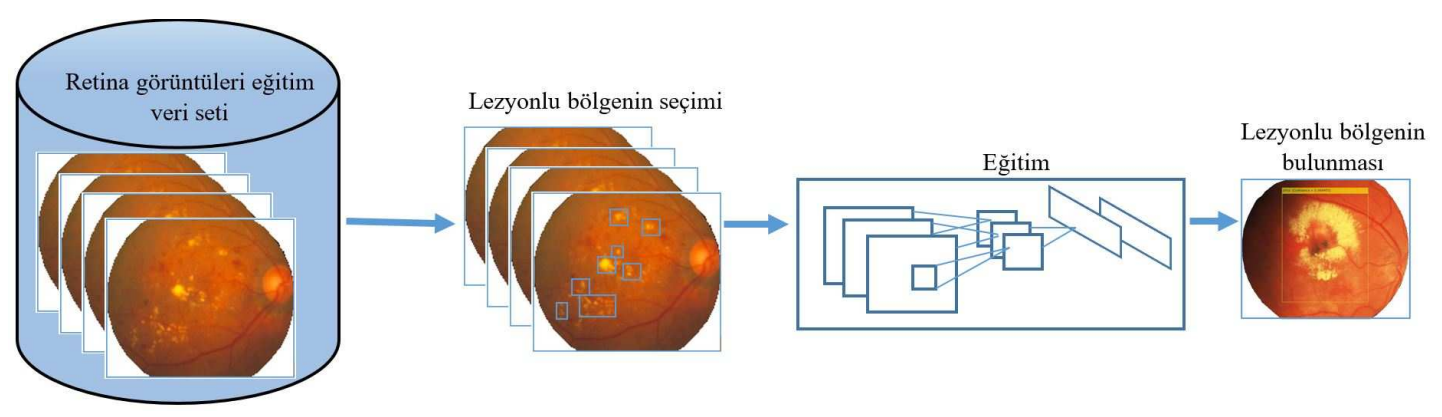

Şekil 1. Önerilen BDTS sistemnin mimarisi ve akış şeması [1]

\section{A. Çalıșmada Kullanılan Veri Seti}

Çalışmada STARE, DIARETDB0 ve DIARETDB1 gibi farklı veri tabanlarından retina görüntüleri kullanılmıştır. Genel olarak görüntülerin \%70’i eğitim görüntüsü, \%30’u ise test görüntüsü olarak ayırılmıştır. Veri setlerindeki DR belirtisi olan bölgeler veri setini oluşturan kişiler tarafından alanında uzmanolan kişilere işaretletimiş görüntülerdir. Veri setinin oluşturulması aşamasında STARE veri seti içerisinde bulunan görüntüler içerisindeki sağlıklı görüntüler ayırt edilmiştir.

1) STARE veri seti: STARE (Hoover, 2000; Hoover \& Goldbaum, 2003) veritabanında bulunan 400 adet görüntüden 358 adet retina görüntüsü alınmıştır. Diğer 42 görüntü ise sağlıklı retina görüntüleri olduğu için çalışmaya dahil edilmemiştir. Görüntüler, $700 \times 605$ çözünürlükte ve 24 bit renk derinliğine sahiptir. 358 adet retina görüntüsünün 108 adeti test aşamasında ve 250 adet retina görüntü ise eğitim aşamasında kullanılmıştır. STARE veritabanında bulunan 358 adet retina görüntüleri üzerinde bulunan lezyonlar farklı hastalıkların belirtisi olabilmektedir. Bu görüntüler üzerindeki lezyonlara bakılarak 2 farklı uzman tarafından yapılan teşhislerde Tablo 2'de gösterilen farklı hastalıklar tespit etmiş ve her bir görüntü için bu hastalıklar ayrı ayrı belirtilmiştir (Goldbaum, 2004).

Tablo 2. STARE veritabanında bulunan retina görüntülerine koyulan teşhisler

\begin{tabular}{cll}
\hline Teşhis Numarası & \multicolumn{1}{c}{ Teşhis } & Kullanılan Kısaltma \\
\hline 1 & Hollenhorst Emboli & Emboli \\
2 & Branch Retinal Artery Occlusion & BRAO \\
3 & Cilio-Retinal Artery Occlusion & CRAO \\
4 & Branch Retinal Vein Occlusion & BRVO \\
5 & Central Retinal Vein Occlusion & CRVO \\
6 & Hemi-Central Retinal Vein Occlusion & Hemi-CRVO \\
7 & Background Diabetic Retinopathy & BDR/NPDR \\
8 & Proliferative Diabetic Retinopathy & PDR \\
9 & Arteriosclerotic Retinopathy & ASR \\
10 & Hypertensive Retinopathy & HTR \\
11 & Coat's & \\
12 & Macroaneurism & \\
13 & Choroidal Neovascularization & CNV \\
\hline
\end{tabular}

Kullanılan görüntüler üzerindeki lezyonlar dağınık ve çok fazla olduklarından bunların tespiti için BESA temelli BDTS'nin eğitim aşamasında kullanılan görüntüler üzerindeki lezyonların etiketlenmesi amacıyla karesel şekilde ve tek görüntü üzerinde birden fazla alanı seçen MATLAB uygulama geliştirilmiştir. Bu sayede 


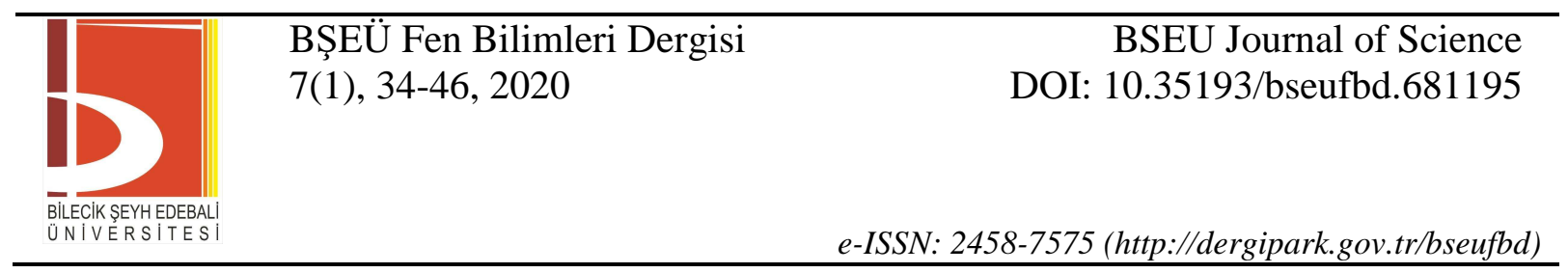

250 adet görüntüden toplamda 2446 bölge işaretlenmiştir. Şekil 2'de retina görüntüleri veri setinde bulunan örnek görüntüler sunulmuştur.
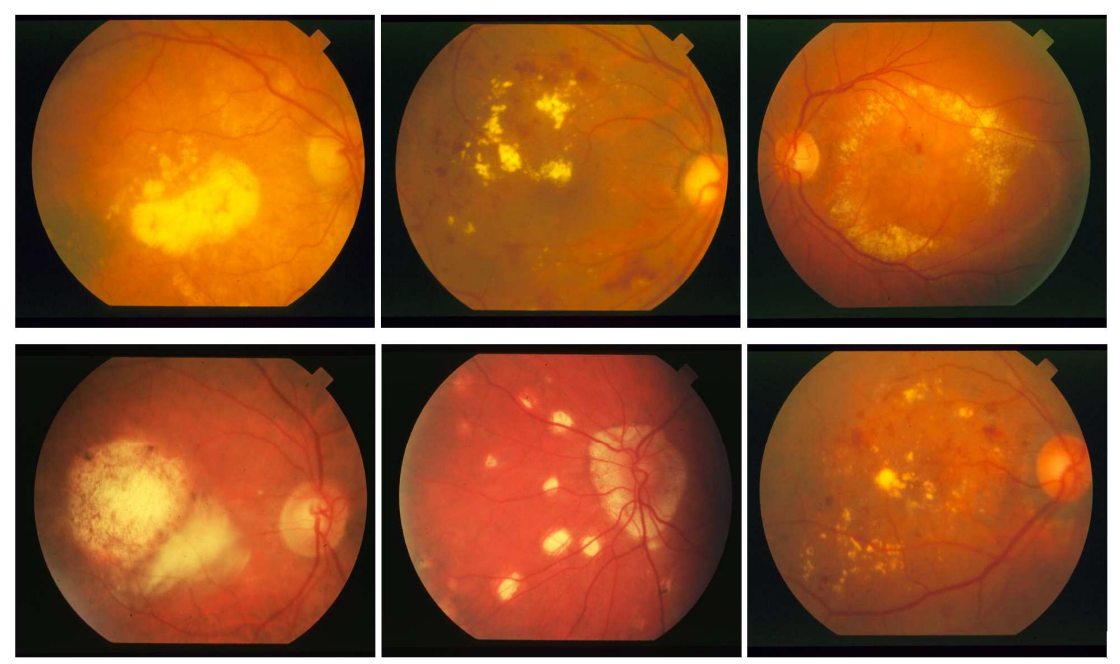

Şekil 2. STARE veri setinde bulunan örnek retina görüntüleri

2) DIARETDBO veri seti: DIARETDB0 [16] veri seti, 20 adeti normal ve 110 adeti DR belirtileri olan (sert eksüda, yumuşak eksüda, mikronanalizmalar, kanamalar ve neovaskülarizasyon) toplam 130 adet renkli retina görüntüsünü içermektedir. Görüntüler 50 derecelik görüş alanına sahip dijital fundus kamera ile elde edilmiştir. Bu veri setindeki görüntüler $1500 \times 1152$ çözünürlüğe sahiptir. Görüntülerden 39 adeti test aşamasında ve 91 adet retina görüntü ise eğitim aşamasında kullanılmıştır. DIARETDB0 veri seti içerisinde bulunan örnek görüntüler Şekil 3'de gösterilmektedir.
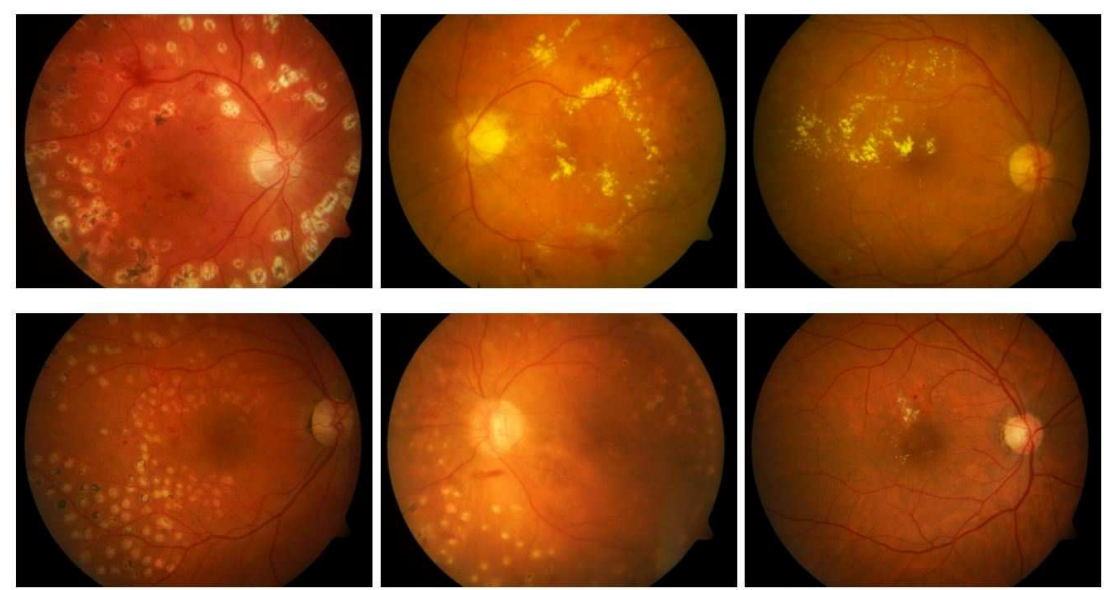

Şekil 3. DIARETDB0 veri setinde bulunan örnek retina görüntüleri

DIARETDB0 veri seti içerisindeki retina görüntülerin her biri üzerinde bulunan DR belirtileri Şekil 4'de gösterildiği işaretlenerek veri seti ile birlikte paylaşılmıştır. Yapılan çalışmada lezyonlu bölgelerin seçimler bu işaretli görüntülerden faydalanılarak yapılmıştır. 


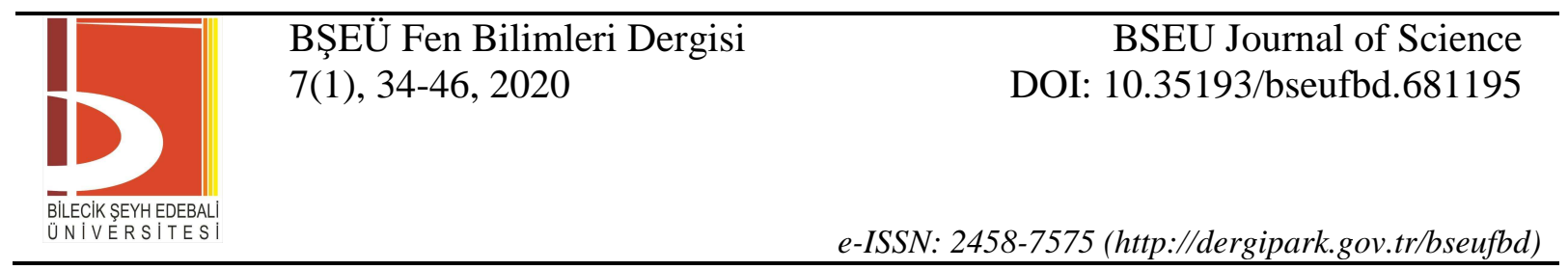

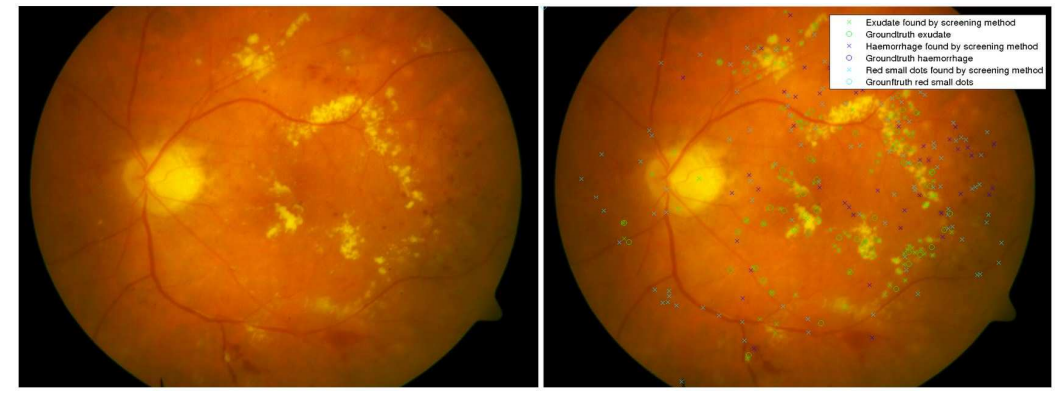

Şekil 4. Orijinal retina görüntüsü ve uzman tarafından işaretlenmiş DR belirtileri

3) DIARETDB1 veri seti: DIARETDB1[17] veri seti, 84 adet DR'nin mikroanevrizmalarını içerdiği 5 adeti ise DR belirtisi içermeyen görüntüler olmak üzere toplam 89 adet renkli retina görüntülerinden oluşmaktadır. Görüntüler 50 derecelik görüş alanına sahip dijital fundus kamera ile elde edilmiştir. Bu veri setindeki görüntüler $1500 \times 1152$ çözünürlüğe sahiptir. Görüntülerden 27 adeti test aşamasında ve 62 adeti ise eğitim aşamasında kullanılmıştır. Şekil 5'de DIARETDB1 veri setinde bulunan örnek retina görüntüleri gösterilmektedir.
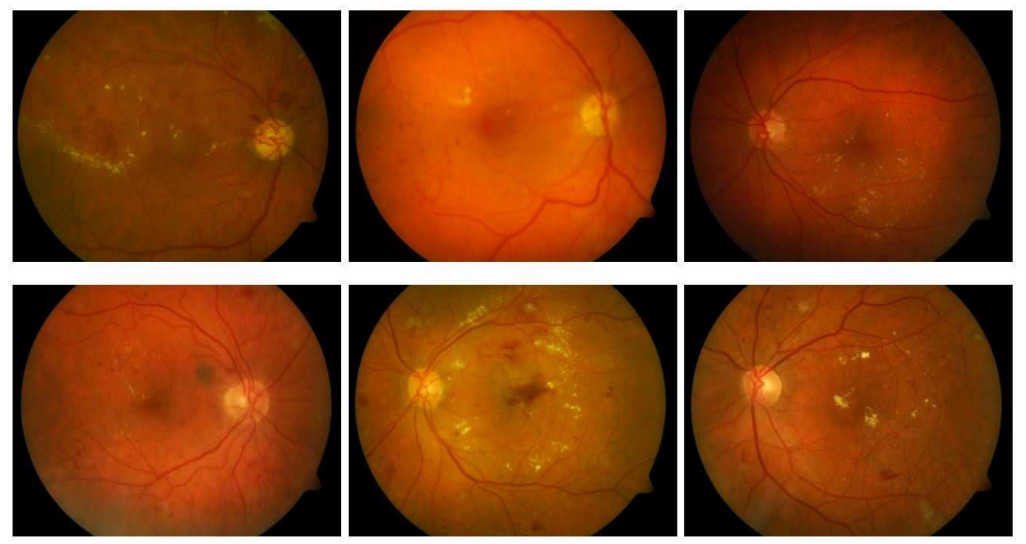

Şekil 5. DIARETDB1 veri setinde bulunan örnek retina görüntüleri

DIARETDB1 veri seti içerisindeki retina görüntülerin her biri üzerinde bulunan DR belirtileri Şekil 6' da gösterildiği işaretlenerek veri seti ile birlikte paylaşılmıştır. Yapılan çalışmada lezyonlu bölgelerin seçimler bu işaretli görüntülerden faydalanılarak yapılmıştır.
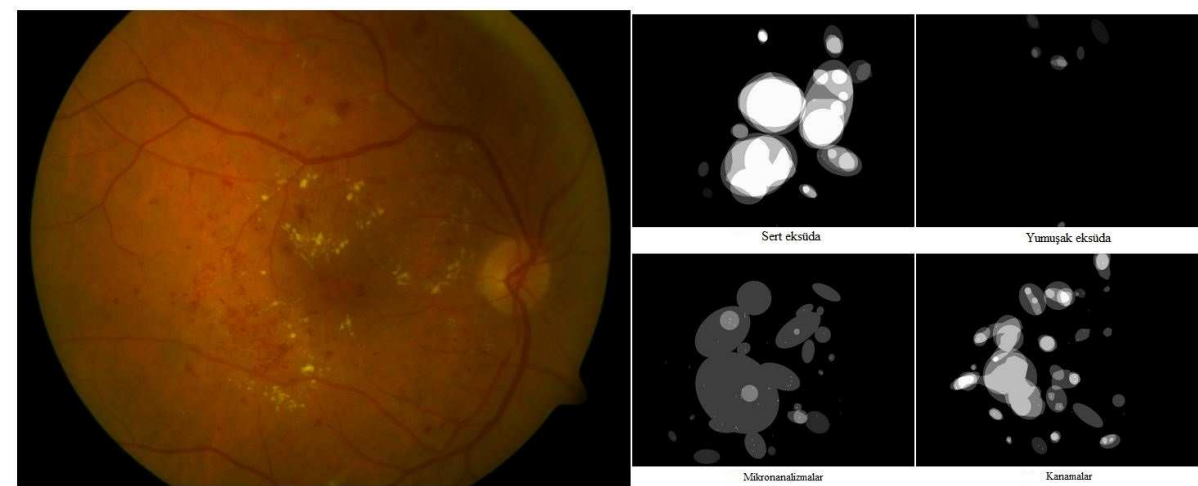

Ojinial givtintil

Şekil 6. Orijinal retina görüntüsü ve uzman tarafından işaretlenmiş DR belirtileri 


\section{B. Bölgesel Evrişimsel Sinir A ğları}

Derin öğrenme, çok büyük sayıda verileri kullanarak bu verilerden denetimli veya denetimsiz olarak özellik çıkarma ve sınıflandırma gibi işlemleri yapabilen çok katmanlı bir yapıya sahip makine öğrenmesinin bir alt sinıfı olarak incelenmektedir [9][18]. Derin öğrenme yöntemlerinden biri olan ESA, sadece görüntü sınıflandırması için kullanılmaz aynı zamanda ham görüntüler üzerinden otomatik bir şekilde özellik çıkarım işlemlerini de gerçekleştirmektedir. Görüntüler üzerindeki özellikleri otomatik olarak seçtiğinden dolayı da nesne tanıma uygulamalarında sıkça kullanılmaktadır. ESA, derin öğrenmenin özelleşmiş bir mimarisidir ve özellikle görüntü işleme uygulamalarında başarılıdır [19]. Nesne tespiti uygulamalarında ESA'lar bir görüntü içerisinde tespit edilmek istenen nesneleri farklı boyutlarda bulabilmektedir. Bundan dolayı çok fazla alanın taraması gerekmektedir. Ayrıca farklı boylardaki nesneleri tanımak için de bütün nesnelerin en boy oranlarını da kontrol etmek zorundadır. Bu gibi çok fazla sayıda bölgede yapılan tarama işlemleri oldukça fazla zaman almaktadır. B-ESA mimarisi ESA mimarisinin bu fazla zaman alan kısmını gidermek amacıyla oluşturulmuş bir ağdır. B-ESA ağlarında evrişim işlemlerinden önce görüntü içerisinde nesne olabilecek alanlar önceden belirlenmektedir. Böylece ağın bakacağı alanlar kısıtlanmış olacak ve yapılan işlemlerin süresi de oldukça azalacaktır [20], [21]. B-ESA'nın alt yapısı bölgesel nesne tanıma öncelikli olduğu için nesne tanıma uygulamalarında ESA ya göre daha fazla tercih edilmektedir [11][22][23].

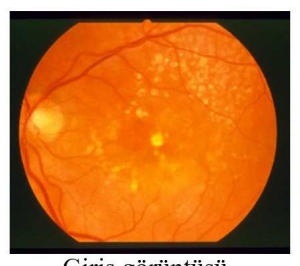

Giriş görüntüsü

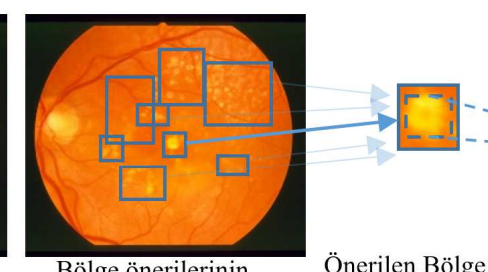

Bölge önerilerinin çıkarılması ( 2000)

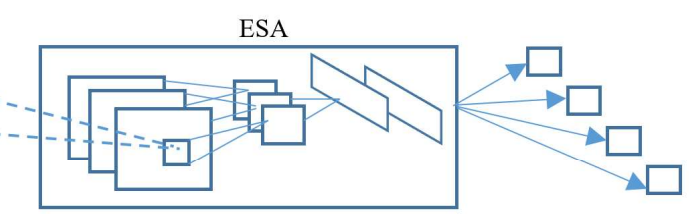

ESA özelliklerinin hesaplanması
Bölgelerin Sınıflandırılması

Şekil 7. B-ESA ağ yapısı [24]

B-ESA ağ yapısı Şekil 7’de gösterilmektedir. Giriş görüntüsü ESA ağına verilmeden önce nesne olması muhtemel bölgeler seçilmektedir. Seçilen her bir bölge ESA ağına verilerek her bir seçilen bölge için özelliklerin hesaplanması sağlanmaktadır. Son aşamada ise sınıflandırma işlemleri yapılmaktadır. B-ESA'da nesne olması muhtemel bölge önerileri için herhangi bir özel algoritma kullanılmaz. Yapılan çalışmada önerilen bölgeler elle belirlenmiş ve Şekil 8'de gösterildiği gibi .mat dosyasına kaydedilmiştir. Belirlenen her bir bölge ayrı ayrı ESA katmanına sokulmaktadır. Burada seçilen bölgeler, çalışmada kullanılan veri setleri içerisinde bulunan ve her bir görüntüdeki lezyonlu bölgeler konunun uzmanları tarafından işaretlenmiş bölgelere bakılarak yapılmıştır.

\section{DENEYSEL ÇALIŞMALAR}

Yapılan çalışmada STARE, DIARETDB0 ve DIARETDB1 veri setinde bulunan retina görüntüleri kullanılarak, bu görüntüler üzerinde bulunan lezyonların tespiti B-ESA tabanlı BDTS sistemi gerçekleştirilmiştir. Çalışmada kullanılan bütün uygulamalar MATLAB ortamında kod geliştirilerek gerçekleştirilmiştir. Çalışma kapsamında gerçekleştirilen bütün uygulamalar özellikleri Tablo 3'de verilen bilgisayar üzerinde gerçekleştirilmiştir.

Tablo 3. Deneysel çalışmalarda kullanılan bilgisayar konfigürasyonu

\begin{tabular}{ll}
\hline Donanım & Özellik \\
\hline Merkezi İşlem Birimi (CPU) & İnel® Core ${ }^{\mathrm{TM}}$ i7-3770 3.40GHz (8 CPUs) \\
Bellek (RAM) & 16 GB (DDR3 166MHz) \\
AnaKart & ASUS P8H77-V LE \\
Grafik Kartı (GPU) & Nvidia GeForce GTX980, 4 GB RAM \\
Harddisk (HDD) & 256 GB SSD HDD \\
\hline
\end{tabular}


B-ESA ağlarında, bölge önerilerinin çıkartılması aşamasında kullanılan ve her bir veri setinde eğitim görüntüleri üzerindeki lezyonların işaretlenmesi amacıyla bir uygulama geliştirilmiştir. Bu uygulama ile bir retina görüntüsü üzerinden sadece bir adet lezyonlu bölge işaretlenmiştir. Sonrasında yapılan eğitim ve test işlemleri sonucunda düşük başarımlar elde edilmiştir. Geliştirilen bu uygulama B-ESA ağlarına daha fazla lezyonlu bölge önerisi sunmak amaciyla tek bir görüntü üzerinden birden fazla lezyonlu bölgeyi seçebilecek şekilde geliştirilmiştir. Bu sayede STARE veri setinde eğitim aşamasında kullanılan 250 adet görüntüden 2446 lezyonlu bölge, DIARETDB0 veri setinde eğitim aşamasında kullanılan 91 adet görüntüden 1547 lezyonlu bölge ve DIARETDB1 veri setinde eğitim aşamasında kullanılan 62 adet görüntüden 801 lezyonlu bölge seçilmiştir. Şekil 8.a'da retina görüntüleri üzerindeki lezyonlu bölgenin seçimi, Şekil 8.b'de ise seçilen bölgelerin konum bilgilerinin “.mat” dosyasına kaydedilmiş halleri görülmektedir. Şekil 8.b’ye bakıldığında sadece bir görüntü için birden fazla farklı alanların seçildiği görülmektedir. Bu şekilde lezyonlu bölgelerle ilgili toplanan birçok veri ile geliştirilen B-ESA tabanlı BDTS sisteminin başarımı arttırılmıştır.

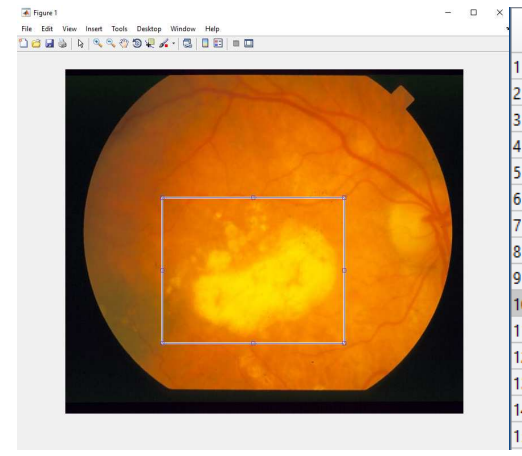

(a)

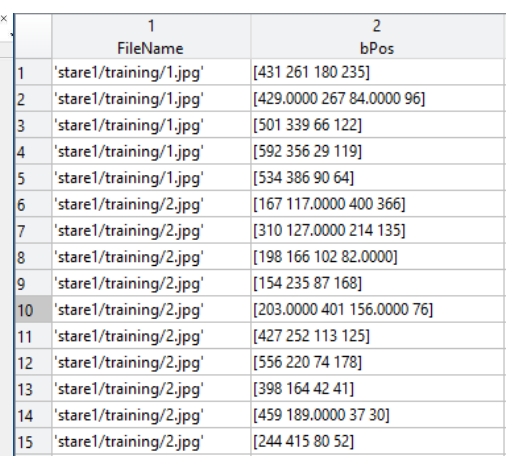

(b)

Şekil 8. Tek görüntü üzerinden birden çok farklı bölgelerin seçim işlemi

Deneysel çalışmada ağın eğitimi retina görüntüleri üzerindeki lezyonlu bölgelerin konum bilgilerinin olduğu “.mat” dosyasının B-ESA ağına sunulmasıyla başlamaktadır. Eğitim algoritması, 0.001 momentum değerinde başlangıç öğrenme oranı, 100 adım sayısı ve 50 tekrarlama sayısı kullanılarak çalıştırılmıştır. Sonrasında her bir retina görüntüsü için test veri seti ile kıyaslama yapılmaktadır. Bu kıyaslama sonucunda geliştirilen sistemin lezyonlu bölgeyi tespit etme başarımını sağlamaktadır. Tablo 4'de eğitim aşamasında elde edilen başarım tablosu görülmektedir.

Tablo 4. ESA eğitim aşamasında elde edilen başarım

\begin{tabular}{ccccccc}
\hline \multirow{2}{*}{ Adım } & \multicolumn{2}{c}{ STARE } & \multicolumn{2}{c}{ DIARETDB0 } & \multicolumn{2}{c}{ DIARETDB1 } \\
\cline { 2 - 7 } Sayısı & Kazanç (\%) & Kayıp & Kazanç (\%) & Kayıp & Kazanç (\%) & Kayıp \\
\cline { 2 - 7 } $\mathbf{9 1}$ & 96.88 & 0.0658 & 95.00 & 0.1523 & 96.72 & 0.0849 \\
$\mathbf{9 3}$ & 97.48 & 0.0612 & 92.97 & 0.1634 & 97.54 & 0.0753 \\
$\mathbf{9 4}$ & 93.37 & 0.0816 & 97.66 & 0.0982 & 96.88 & 0.0895 \\
$\mathbf{9 5}$ & 98.44 & 0.0587 & 89.84 & 0.2384 & 100.00 & 0.0322 \\
$\mathbf{9 6}$ & 99.22 & 0.0505 & 97.66 & 0.0833 & 95.31 & 0.1292 \\
$\mathbf{9 7}$ & 98.36 & 0.0505 & 94.53 & 0.1227 & 99.22 & 0.0590 \\
$\mathbf{9 8}$ & 99.19 & 0.0324 & 96.85 & 0.1522 & 95.31 & 0.1261 \\
$\mathbf{9 9}$ & 100.00 & 0.0177 & 94.53 & 0.1296 & 93.75 & 0.1871 \\
$\mathbf{1 0 0}$ & 100.00 & 0.0128 & 93.44 & 0.1372 & 95.31 & 0.0971 \\
\hline
\end{tabular}




\begin{tabular}{|c|c|c|}
\hline & $\begin{array}{l}\text { BŞEÜ Fen Bilimleri Dergisi } \\
7(1), 34-46,2020\end{array}$ & $\begin{array}{r}\text { BSEU Journal of Science } \\
\text { DOI: } 10.35193 / \text { bseufbd.681195 }\end{array}$ \\
\hline $\begin{array}{l}\text { BlLECIKSEYHEDEBAL } \\
\text { UNIVERSITESI }\end{array}$ & & 58-7575 (http://dergipark.gov.tr/bseufbd) \\
\hline
\end{tabular}

Yapılan eğitimler sonucunda ağ test görüntüleri üzerinde test edilmiş ve lezyonlu bölgeyi tespit etme başarımı STARE, DIARETDB0 ve DIARETDB1 veri setleri için sırasılla \%91, \%98.53 ve \%93.01 olarak ölçülmüştür. Yapılan çalışmadan elde edilen başarımların literatür ile karşılaştırılması Tablo 5'de gösterilmektedir.

Tablo 5. Yapılan çalışmanın literatürde yapılan çalışmalarla karşıllaştırılması

\begin{tabular}{lcccc}
\hline Çalışmalar & \multicolumn{3}{c}{ Başarım (\%) } \\
\cline { 2 - 5 } & Açıklama & STARE & DIARETDB0 & DIARETDB1 \\
\hline Atilla vd. [7] & & - & 95.8 & 92.4 \\
[5] & & 85 & 92 & - \\
Carrera vd. [8] & Messidor Veri Seti & - & - & - \\
Kasım [4] & DRIVE Veri Seti & 86 & - & - \\
Sighn [3] & Messidor Veri Seti & - & - & - \\
Rocha [1] & Messidor Veri Seti & - & - & 96.6 \\
Sunulan Çalışma & & $\mathbf{9 1 . 0 0}$ & $\mathbf{9 8 . 5 3}$ & $\mathbf{9 3 . 0 1}$ \\
\hline
\end{tabular}

Yapılan deneysel çalışmalar sonucunda önerilen B-ESA temelli BDTS sisteminin kullanılan veri setlerindeki retina görüntüleri üzerindeki lezyonlu bölgeyi başlarılı bir şekilde bulduğu örnek görüntüler Şekil 9'da gösterilmektedir.

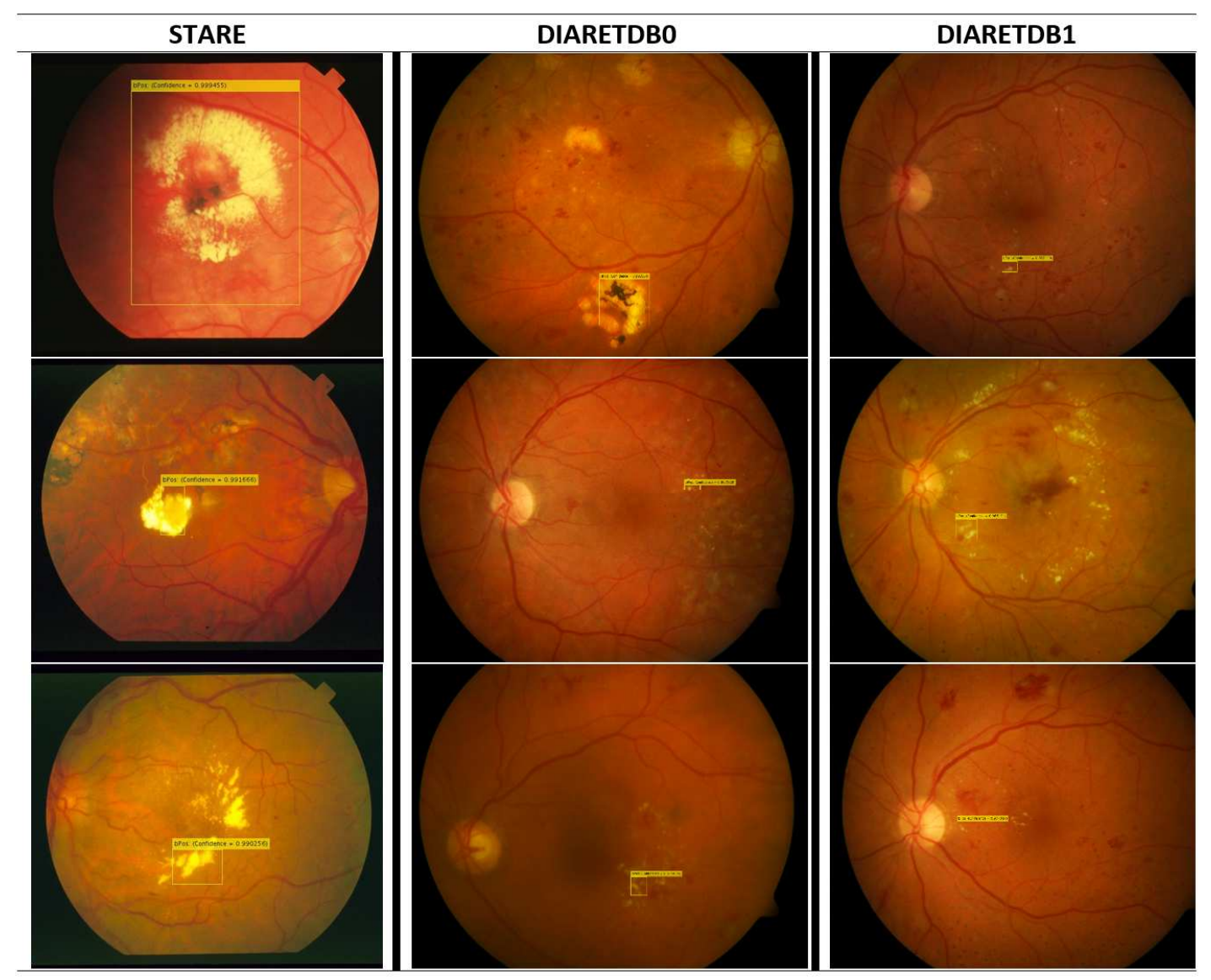

Şekil 9. Retina görüntüleri üzerindeki lezyonlu bölgelerin iyi derecede sınıflandırılma sonuçları için örnek çerçeveler 


\begin{tabular}{|c|c|c|}
\hline & $\begin{array}{l}\text { BŞEÜ Fen Bilimleri Dergisi } \\
7(1), 34-46,2020\end{array}$ & $\begin{array}{l}\text { BSEU Journal of Science } \\
\text { DOI: } 10.35193 / \text { bseufbd } 681195\end{array}$ \\
\hline & & 58-7575 (http://dergipark.gov.tr/bseufbd) \\
\hline
\end{tabular}

Şekil 10'da geliştirilen sistemin lezyonlu bölge yerine göz merceğini bulduğu görülmektedir. Bunun sebebi ise göz merceğinin yapısının lezyonların yapısına çok benzemesinden kaynaklanmaktadır. Bu sorunun üstesinden gelmek için seçilen lezyonlu bölge sayısının arttırılması gerekmektedir. Ayrıca lezyonlu bölgeleri çok farklı açılardan seçilmesi de bu gibi sorunların üstesinden gelmek için izlenecek yollardan biri olabilir.

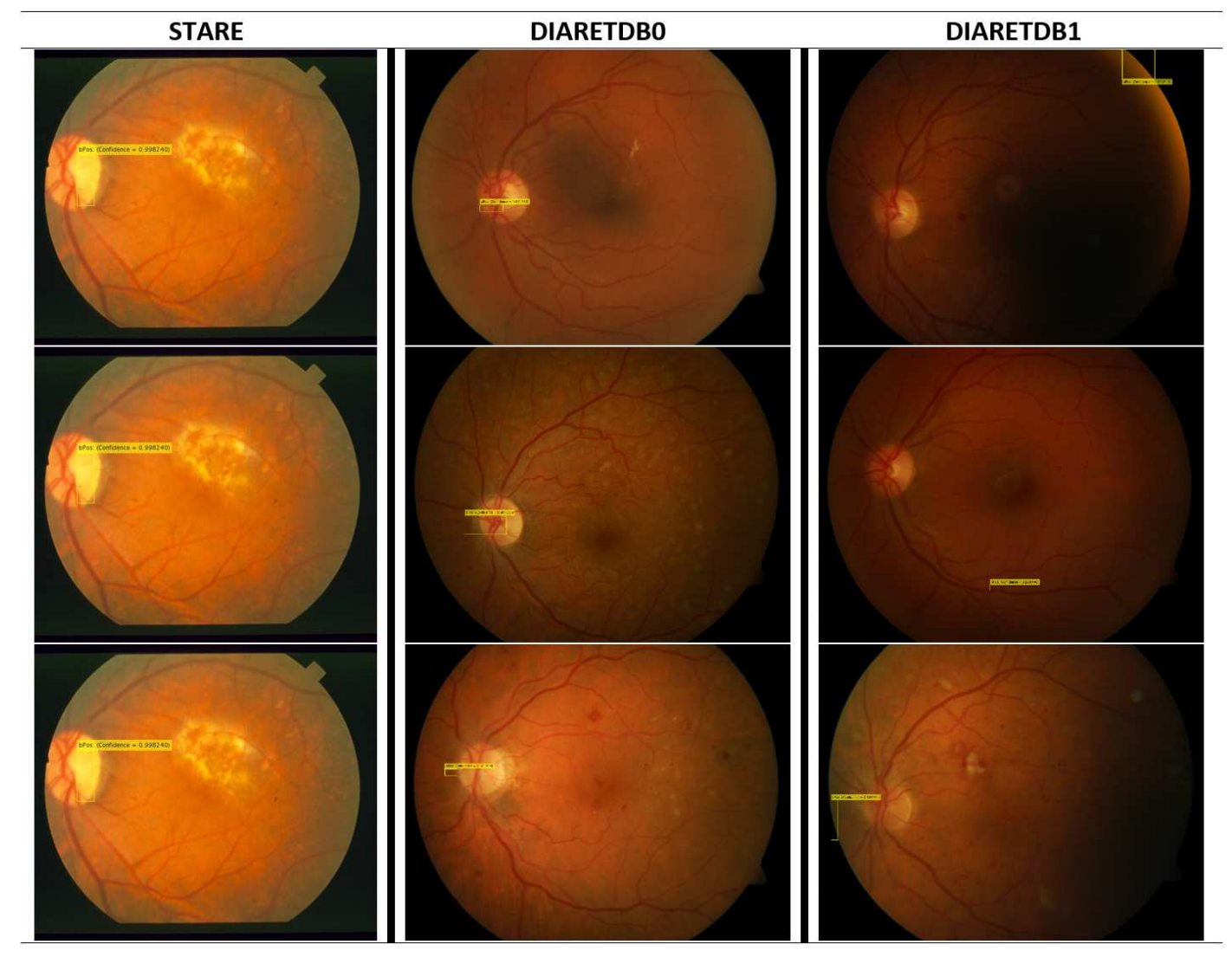

Şekil 10. Geliştirilen sistemin retina görüntüleri üzerindeki lezyon dışındaki bölgeleri bulduğu sonuçlar için örnek çerçeveler

\section{SONUÇLAR}

Retina görüntülerindeki lezyonlu bölgelerin önceden tespit edilmesi hastalığın teşhis ve tedavisi için kritik öneme sahiptir. Yapılan bu çalışmada, retina görüntüleri üzerinde bulunan lezyonların tespit edilmesi amacıyla B-ESA temelli BDTS sistemi önerilmiştir. Önerilen bu sistem ile DR'nin erken teşhis ve tedavisinde göz hastalıkları alanında çalışan uzmanlara yardımcı olması öngörülmektedir. Bu amaçla deneysel çalışmalar STARE, DIARETDB0 ve DIARETDB1 gloabl veri setleri üzerinde gerçekleştirilmiştir. Veri setlerinnden elde edilen görüntüler \%70'i eğitim ve \%30’u test aşamasında kullanılmak üzere ayrılmıştır. Eğitim aşamasından önce eğitimde kullanılan görüntüler üzerindeki lezyonlar etiketlenmiştir. Geliştirilen B-ESA temelli BDTS sistemine uygun olacak şekilde etiketleme işlemini gerçekleştirecek çoklu alan seçme özelliğine sahip bir uygulama geliştirilmiştir. Bu uygulama ile gözün farklı bölgelerinde bulunan lezyonların işaretlenmesi sağlanmıştır. Lezyoınlu bölgelerin işaretlenmesinden sonra B-ESA ağına işaretli bölge bilgileri ve eğitim görüntüleri verilerek eğitim yapılmıştır.

Yapılan eğitimler sonucunda ağın daha önce hiç görmediği test görüntüleri üzerinde testler gerçekleştirilmiştir. Test çalışmaları sonucunda STARE veri seti üzerinde \%91, DIARETDB0 veri seti üzerinde $\% 98.53$ ve DIARETDB1 veri seti üzerinde \%93.01 doğrulukla lezyonlu bölgelerin tespit edildiği 
gözlemlenmiştir. Deneysel sonuçlar göre, literatürde retina görüntüleri üzerindeki lezyonların tespit edilmesi çalışmalarında önerilen sistemin daha iyi sonuç verdiği görülmektedir. Sonraki çalışmalarda B-ESA'nın test görüntüleri üzerinde lezyon olma ihtimali olan birden fazla alanın bulunarak işaretlenmesi sağlanacaktır. Ayrıca yapılan bu çalışma Hızlı B-ESA, Daha Hızlı B-ESA ve Mask B-ESA teknikleri ile de test edilerek en iyi sonucu veren derin öğrenme ağ modeli tespiti de yapılacaktır.

\section{KAYNAKLAR}

[1] Rocha, A., Carvalho, T., Jelinek, H. F., Goldenstein, S., \& Wainer, J. (2012). Points of interest and visual dictionaries for automatic retinal lesion detection. IEEE Transactions on Biomedical Engineering, 59(8), 2244-2253. https://doi.org/10.1109/TBME.2012.

[2] Salomão, S. R., Mitsuhiro, M. R. K. H., \& Belfort Jr, R. (2009). Visual impairment and blindness: an overview of prevalence and causes in Brazil. Anais Da Academia Brasileira de Ciências, 81(3), 539-549. https://doi.org/10.1590/S0001-37652009000300017.

[3] Singh, T. M., Bharali, P., \& Bhuyan, C. (2019). Automated detection of diabetic retinopathy. In 2019 2nd International Conference on Advanced Computational and Communication Paradigms, ICACCP 2019. Institute of Electrical and Electronics Engineers Inc. https://doi.org/10.1109/ICACCP.2019.8882914.

[4] Kasim, Ö. (2018). Detection of lesions on the retina image. In 26th IEEE Signal Processing and Communications Applications Conference, SIU $2018 \quad$ (pp. 1-4). IEEE. https://doi.org/10.1109/SIU.2018.8404532.

[5] Quellec, G., Russell, S. R., \& Abràmoff, M. D. (2011). Optimal Filter Framework for Automated, Instantaneous Detection of Lesions in Retinal Images. IEEE Transactions on Medical Imaging, 30(2), 523-533. https://doi.org/10.1109/TMI.2010.2089383.

[6] Murugan, R., Albert, A. J., \& Nayak, D. K. (2019). An Automatic Localization of Microaneurysms in Retinal Fundus Images. In 6th IEEE International Conference on Smart Structures and Systems ICSSS 2019. Institute of Electrical and Electronics Engineers Inc. https://doi.org/10.1109/ICSSS.2019.8882858.

[7] Atila, Ü., Akyol, K., \& Sabaz, F. (2020). Retinal Görüntülerde Eksuda Lezyonlarının Tespiti Üzerine Bir Çalışma. Bilişim Teknolojileri Dergisi, 13(1), 27-36. https://doi.org/10.17671/gazibtd.550022

[8] Carrera, E. V., Gonzalez, A., \& Carrera, R. (2017). Automated detection of diabetic retinopathy using SVM. In 2017 IEEE XXIV International Conference on Electronics, Electrical Engineering and Computing (INTERCON) (pp. 1-4). IEEE. https://doi.org/10.1109/INTERCON.2017.8079692.

[9] Dandıl, E., Turkan, M., Boğa, M., \& Çevik, K. K. (2019). Daha Hızlı Bölgesel-Evrişimsel Sinir Ağları ile Sığır Yüzlerinin Tanınması. Bilecik Şeyh Edebali Üniversitesi Fen Bilimleri Dergisi, 6, 177-189. https://doi.org/10.35193/bseufbd.592099

[10] Çevik, K. K., \& Dandıl, E. (2019). Classification of Lung Nodules Using Convolutional Neural Networks on CT Images. In 2nd International Turkish World Engineering and Science Congress (pp. 27-35). Retrieved from https://www.researchgate.net/publication/338385647_Classification_of_Lung_Nodules_Using_Convoluti onal_Neural_Networks_on_CT_Images

[11] Ari, A., \& Hanbay, D. (2019). Tumor detection in MR images of regional convolutional neural networks. Journal of the Faculty of Engineering and Architecture of Gazi University, 34(3), 1395-1408. https://doi.org/10.17341/gazimmfd.460535. 
[12] Dandil, E., \& Polattimur, R. (2019). Daha hızlı bölgesel evrişimsel sinir ağları ile köpek davranışlarının tanınması ve takibi. Gazi Üniversitesi Mühendislik-Mimarlık Fakültesi Dergisi, 35(2), 819-834. https://doi.org/10.17341/gazimmfd.541677.

[13] Hoover, A. (2000). Locating blood vessels in retinal images by piecewise threshold probing of a matched filter response. IEEE Transactions on Medical Imaging, 19(3), 203-210. https://doi.org/10.1109/42.845178.

[14] Hoover, A., \& Goldbaum, M. (2003). Locating the optic nerve in a retinal image using the fuzzy convergence of the blood vessels. IEEE Transactions on Medical Imaging, 22(8), 951-958. https://doi.org/10.1109/TMI.2003.815900

[15] He, K., Zhang, X., Ren, S., \& Sun, J. (2016). Deep residual learning for image recognition. In Proceedings of the IEEE Computer Society Conference on Computer Vision and Pattern Recognition (Vol. 2016-Decem, pp. 770-778). IEEE Computer Society. https://doi.org/10.1109/CVPR.2016.90.

[16] Kauppi, T., Kalesnykiene, V., Kamarainen, J.-K., Lensu, L., Sorri, I., Uusitalo, H., Kälviäinen, H., Pietilä, J. (2007). DIARETDB0: Evaluation Database and Methodology for Diabetic Retinopathy Algorithms. Retrieved from https://www.it.lut.fi/project/imageret/diaretdb0/doc/diaretdb0_techreport_v_1_1.pdf

[17] Kauppi Tomi, Kalesnykiene Valentina, Sorri Iiris, Raninen Asta, Voutilainen Raija, Kamarainen Joni, L. L. and U. H. (2009). DiaRetDB1: Diabetic Retinopathy Database and Evaluation Protocol. Retrieved from http://www.it.lut.fi/project/imageret/diaretdb1_v2_1/

[18] Nie, X., Duan, M., Ding, H., Hu, B., \& Wong, E. K. (2020). Attention Mask R-CNN for Ship Detection and Segmentation From Remote Sensing Images. IEEE Access, 8, 9325-9334. https://doi.org/10.1109/ACCESS.2020.2964540

[19] Rodin, C. D., de Lima, L. N., de Alcantara Andrade, F. A., Haddad, D. B., Johansen, T. A., \& Storvold, R. (2018). Object Classification in Thermal Images using Convolutional Neural Networks for Search and Rescue Missions with Unmanned Aerial Systems. In 2018 International Joint Conference on Neural Networks (IJCNN) (Vol. 2018-July, pp. 1-8). IEEE. https://doi.org/10.1109/IJCNN.2018.848946

[20] İnik, Ö., \& Ülker, E. (2017). Gaziosmanpaşa Bilimsel Araştırma Dergisi (GBAD) Gaziosmanpasa Journal of Scientific Research Derin Öğrenme ve Görüntü Analizinde Kullanılan Derin Öğrenme Modelleri. GAZİOSMANPAŞBilimsel AraştirmDergisi, 6(3), 85-104. Retrieved from http://dergipark.gov.tr/gbad

[21] Le, P.-P., Nguyen, V.-T., Guo, S.-M., Tu, C.-T., \& Lien, J.-J. J. (2019). Visual-Guided Robot Arm Using Multi-Task Faster. 2019 International Conference on Technologies and Applications of Artificial Intelligence (TAAI), 2-7. https://doi.org/10.1109/TAAI48200.2019.8959938

[22] Fang, F., Li, L., Zhu, H., \& Lim, J.-H. (2019). Combining Faster R-CNN and Model-Driven Clustering for Elongated Object Detection. IEEE Transactions on Image Processing, 29, 1-1. https://doi.org/10.1109/tip.2019.2947792

[23] He, K., Gkioxari, G., Dollár, P., \& Girshick, R. (2020). Mask R-CNN. IEEE Transactions on Pattern Analysis and Machine Intelligence, 42(2), 386-397. https://doi.org/10.1109/TPAMI.2018.2844175

[24] Girshick, R., Donahue, J., Darrell, T., \& Malik, J. (2014). Rich Feature Hierarchies for Accurate Object Detection and Semantic Segmentation. In 2014 IEEE Conference on Computer Vision and Pattern Recognition (pp. 580-587). IEEE. https://doi.org/10.1109/CVPR.2014.81 